\title{
A Study of Prevalence of Hepatitis-B and Hepatitis-C Infection in Thalassemic Patients in a Tertiary Care Hospital, Jamnagar, Gujarat, India
}

\author{
Chandani C. Surani, Ruchi V. Shah* and Mala Sinha \\ Department of Microbiology, Shri M.P. Shah Government Medical College and GGG \\ Hospital, Jamnagar, Gujarat, India \\ *Corresponding author
}

\section{A B S T R A C T}

\begin{tabular}{|l|}
\hline Key w or d s \\
Thalassemia, \\
Hepatitis B, \\
$\begin{array}{l}\text { Hepatitis C, ELISA, } \\
\text { Blood transfusion }\end{array}$ \\
\hline Article Info \\
\hline $\begin{array}{l}\text { Accepted: } \\
\text { 22 April } 2018 \\
\text { Available Online: } \\
\text { 10 May 2018 }\end{array}$ \\
\hline
\end{tabular}

Thalassemia is an autosomal recessive disease causing haemolytic anaemia. The ideal treatment of these patients involves regular, 2-4 weekly blood transfusions. The major complications by this treatment are the transmission of transfusion acquired infections such as Hepatitis B virus infection, Hepatitis C virus infection, Human immunodeficiency virus infection, Syphilis, Malaria and transfusion acquired iron overload. Aim of the study is to evaluate the prevalence of Hepatitis B \& C among Thalassemic patients transmitted by blood transfusion. Retrospective study was conducted in Microbiology department, Shri M.P. Shah medical college and GGG hospital, Jamnagar from January 2016 to June 2017. Patients with thalassaemia having regular blood transfusions at this hospital were enrolled. 200 serum samples were tested by using ELISA Kits for HBsAg and Anti HCV. Out of 200 patients $119(59.5 \%)$ were male and $81(40.5 \%)$ were females. Out of them $02(1 \%)$ $\mathrm{HBsAg}$ positive and $10(5 \%)$ Anti-HCV reactive. More sensitive screening tests, stringent donor selection and vaccinating all children at the time of induction into the thalassemia transfusion programme are required for the better control of this transfusion - transmitted infections among Thalassemia patients.

\section{Introduction}

The Thalassemia is one of the most common genetic diseases in the world. They form a heterogonous group of conditions resulting from a wide variety of mutations of genes which code for hemoglobin synthesis. Beta thalassemia major is the homozygous form, inherited recessively and resulting in reduced or absent beta chain production (Ahmed Kamel Mansour et al., 2012). The ideal treatment of these patients involves regular, 24 weekly blood transfusions. The major complications by this treatment are the transmission of transfusion acquired infections such as Hepatitis B virus (HBV) infection, Hepatitis C virus (HCV) infection, Human immunodeficiency virus (HIV) infection, Syphilis, Malaria and transfusion acquired iron overload (Hamid Hussain et al., 2008).

According to the World Health Organization (WHO), approximately 240 million people are chronically infected with HBV worldwide, while 150 million people are infected with HCV (HardikBhavsar et al., 2011). The 
general incidence of thalassemia trait in India varies between 3 and $17 \%$. The prevalence of $\mathrm{HCV}$ infection among thalassemic patients in India ranged from $7 \%$ to $25 \%$ in different reports whereas prevalence of Hepatitis B in thalassemic patients in India has varied between $1 \%$ to $6.4 \%$ (HardikBhavsar et al., 2011).

The aim of present study was to investigate the true prevalence of $\mathrm{HBV}$ and $\mathrm{HCV}$ in patients with thalassemia and to assess $\mathrm{HCV}$ and $\mathrm{HBV}$ infection associated risk factors.

\section{Materials and Methods}

This study is undertaken to determine prevalence of Hepatitis B virus surface antigen (HBsAg), and antibody to Hepatitis C (anti$\mathrm{HCV}$ ) virus, among thalassemic patient attending, Tertiary Care Hospital, Jamnagar, Gujarat, India. Serum from 200 cases was collected from January 2016 to June 2017.

\section{Inclusion criteria}

All known thalassemic patients.

\section{Exclusion criteria}

Unknown thalassemic patients.

Patients which have other viral hepatitis.

Other sample like fluids.

Demographic data such as age, duration and number of blood transfusions, history of HBV vaccination were obtained from detailed interviewing of the patient and/or guardians. The material collected was whole blood using sterile disposable syringes under aseptic precautions. $5 \mathrm{ml}$ of blood was withdrawn by venipuncture aseptically and it was collected in a plain vial without adding any anticoagulant. The blood was centrifuged and clear serum was transferred into provials. The serum samples were subjected to ELISA as per kit instructions for the following viral markers. The optical density (OD value) value was taken in ELISA reader and cut off value was calculated as per manufacturers guidelines.

\section{Hepatitis B virus surface antigen (ERBALISA ${ }^{\circledR}$ ELISA HBsAg)}

Cut-off Value $=$ Average $\mathrm{NC}+0.15$

(Negative control mean $(\mathrm{NCX})=$ Absorbance value of Negative controls / Number of Negative Control)

All samples with absorbance value less than the Cut-off Value should consider Negative and absorbance value more than the Cut-off Value should consider Positive for HBsAg.

\section{Antibody Hepatitis C virus (QUALISA $^{\circledR}$ ELISA HCV)}

Cut-off Value $=$ Average $\mathrm{NC}+0.3$

(Negative control mean $(\mathrm{NCX})=$ Absorbance value of Negative controls / Number of Negative Control)

All samples with absorbance value less than the Cut-off Value should consider Nonreactive and absorbance value more than the Cut-off Value should consider Reactive for $\mathrm{HCV}$ antibody.

\section{Results and Discussion}

A total of 200 patients with thalassemia were evaluated over a period of one and half years. Out of 200 thalassemic patients 119 (59.5\%) were males and $81(40.5 \%)$ were females. Amongst 200 patients with thalassemia 5.0\% were $\mathrm{HCV}$ positive and only $1.0 \%$ were $\mathrm{HBV}$ positive. Seroprevalence of $\mathrm{HCV}$ among males was $7.56 \%$ in males and $1.2 \%$ in females. Seroprevalence of HBsAg among 
males was $0.84 \%$ in males and $1.2 \%$ in females. Amongst HCV positive patients with thalassemia, highest prevalence $(7.5 \%)$ was found to be in the age group of 9-12 years. Amongst HBsAg positive patients with thalassemia, highest prevalence $(2.8 \%)$ was found to be in the age group of 2-4years.

Highest seroprevalence of $\mathrm{HCV}$ was seen in patients having more than 100 transfusions (40\%) and lowest was seen in patients having less than 50 transfusions. Higher seroprevalence of $\mathrm{HCV}$ was associated with more number of transfusions whereas with Hepatitis B no such association was seen.

Highest seroprevalence of Hepatitis B was seen among non-vaccinated patients (4\%). No cases of Hepatitis B were seen in patients who were vaccinated.

The HCV infection is a widespread disease that affects a large number of thalassemia patients worldwide and is considered as a major public health problem in these high risk groups Transfusion-transmitted infections such as Hepatitis B Virus (HBV), Hepatitis C Virus (HCV), and HIV are dreaded consequences of transfusions, as these can result in long-term morbidity and mortality. In India, it is mandatory to screen donated blood for HIV (since 1996), anti-HCV (since 2001), HBs antigen (since 1996), syphilis and malaria.

In our study shows $1.0 \%$ prevalence of HBsAg among Thalassemic patients, which is lower than other study like Modi et al., (2016) (4.3\%), Kataky et al., (2001) (6.6\%), Wonke et al., (1992) (7.4\%) and comparable to other study like Emothal et al., (2007) (0.8\%), Satia et al., (2016) (1.4\%) and Shaharam et al., (2006) (1.5\%). In our study shows HCV prevalence rate of $5.0 \%$ among Thalassemic patients, which is lower than other study like Wonke et al., (1992) (11.1\%), Satia et al., (2016) (18.6\%) and Modi et al., (2016) (20.4\%) and comparable to other study like Chakrabarti et al., (2006) (5.0\%) and Kataky et al., 2001(3.3\%).

Table.1 Sex-wise distribution of HBsAg and Anti HCV in Thalassemia patients

\begin{tabular}{|l|l|l|l|}
\hline Gender & No. of patients & HBsAg Positive & Anti-HCV Reactive \\
\hline Male & 119 & $1(0.84 \%)$ & $9(7.56 \%)$ \\
\hline Female & 81 & $1(1.2 \%)$ & $1(1.2 \%)$ \\
\hline Total & 200 & $2(1.0 \%)$ & $10(5.0 \%)$ \\
\hline
\end{tabular}

Table.2 Age wise distribution of HBsAg and Anti HCV in Thalassemia patients

\begin{tabular}{|l|l|l|l|}
\hline Age Group & No. of patients & HBsAg Positive & Anti-HCV Reactive \\
\hline <2 year & 7 & - & - \\
\hline 2-4 Year & 35 & $1(2.8 \%)$ & $2(5.7 \%)$ \\
\hline 5-8 Year & 53 & - & $2(3.7 \%)$ \\
\hline 9-12 Year & 40 & - & $3(7.5 \%)$ \\
\hline >12 Year & 65 & $1(1.5 \%)$ & $3(4.6 \%)$ \\
\hline
\end{tabular}


Table.3 Seroprevalence of Hepatitis B and Hepatitis C in association with number of blood transfusions

\begin{tabular}{|c|c|c|c|}
\hline No. of Transfusion & No. of patients & HBsAg Positive & Anti-HCV Reactive \\
\hline $\mathbf{0 - 2 5}$ & 72 & $1(1.38 \%)$ & - \\
\hline $\mathbf{2 6 - 5 0}$ & 70 & - & - \\
\hline $\mathbf{5 1 - 7 5}$ & 26 & $1(3.84 \%)$ & $2(7.69 \%)$ \\
\hline $\mathbf{7 6 - 1 0 0}$ & 22 & - & $4(18.18 \%)$ \\
\hline$>100$ & 10 & - & $4(40.0 \%)$ \\
\hline
\end{tabular}

Table.4 Seroprevalence of Hepatitis B in thalassemia patients in association with their vaccination status

\begin{tabular}{|c|c|c|c|}
\hline Vaccination Status & No. of patients & HBsAg Positive & HBsAg Negative \\
\hline Immunized & 150 & $0(0)$ & $150(100 \%)$ \\
\hline Non Immunized & 50 & $2(4 \%)$ & $48(96 \%)$ \\
\hline
\end{tabular}

There was no statistical significant difference among male and female patients. HCV infection was found to be highly prevalent amongst transfusion associated infection. The major reason for this could be non-availability of vaccine against HCV. Thalassemia patients may acquire hepatitis $\mathrm{C}$ through the administration of $\mathrm{HCV}$-infected blood collected during the donor window period (Table 1-4).

Our study reported lower prevalence of HBV, which might be due to the free availability of hepatitis $\mathrm{B}$ vaccine and better understanding of parents about HBV vaccination and inclusion of Hepatitis B vaccine in National immunisation program where first dose of hepatitis B vaccine is given at birth. In our study seroprevalence of $\mathrm{HBs}$ antigen was seen only in non-vaccinated. Similar findings have been reported by Satia et al., (2016). Therefore, preventive measures, especially HBV vaccination should be given to all especially thalassaemia patients.

Patients with thalassemia major are at higher risk of developing hepatitis due to transfusion of blood from donor infected with hepatitis B virus (HBV). To decrease prevalence of $\mathrm{HBV}$ infection emphasizes the need for routine screening of donor's blood for HBV infection and also the need for vaccinating all children at the time of induction into the thalassemia transfusion programme. In our study, a high prevalence of $\mathrm{HCV}$ seropositivity (5\%) was observed.

As there is no vaccine available for Hepatitis $\mathrm{C}$ the only way of reducing the prevalence of $\mathrm{HCV}$ in multiple transfused thalassemic patients by effective screening of blood. Screening of blood by ELISA technique is ineffective as ELISA techniques are unable to detect these viruses in window period.

Therefore nucleic acid amplification techniques should be made mandatory for screening of blood for hepatitis B and C in developing countries like India to reduce the prevalence of hepatitis $\mathrm{C}$ infection.

\section{Acknowledgement}

I express my heartfelt thanks and gratitude to my institution, Shri M.P. Shah Govt. medical college and GGG hospital, Jamnagar for allowing me to conduct the study. 


\section{References}

Ahmed Kamel Mansour, A. Rabab Mahfouz Aly. Prevalence of $\mathrm{HBV}$ and $\mathrm{HCV}$ infection among multi-transfused Egyptian thalassemic patients. Hematol Oncol Stem Cell Ther., 2012; 5(1): 5459.

Chakrabarti S., Pradhan P., Roy A, et al., Prevalence of anti HCV, HBsAg in high risk recipients of blood products dept of pathology NRS. Med. College Kolkata. Indian J. Public health, 2006; 50(1): 4344.

Emothal R ivistaItaliana di Medicinadell' Adolescenza - Volume 5, n. 3, 2007

Hamid Hussain, Rashid Iqbal, Muhammad Hussain Khan, BushraIftikhar, Sabina Aziz, Fayaz Khan Burki, JunaidSethi, Mumtaz Hassan, Yasir Bin Nisar, Jai Krishan Prevalence Of Hepatitis C In Beta Thalassaemia Major Gomal Journal Of Medical Sciences., JulyDecember 2008; 6(2)

Hardik Bhavsar, Kanu Patel. Prevalence of HIV, Hepatitis B and Hepatitis C infection in Thalassemia major patients in tertiary care hospital. NJIRM. 2011; 2(3): 0975-984.

Kataky N prevalence of hepatitis B \& hepatitis $\mathrm{C}$ infection in multiply transfused thalassemic patients. (nov.2001)

Modi d, rathodgb, delwadiakn, goswami hm. Study of seroprevalence in thalassemic patients. Iaim, 2016; 3(4): 5765.

Satia et al., seroprevalence of hepatitis b and hepatitis c among thalassemia Patients at a tertiary care hospital in north indiaejpmr, 2016, 3(8), 608-611.

Shaharam M., et al., Epidemiology of HBV, $\mathrm{HCV}$, in patients with beta thalassemia major in Iran a multicentric study. Archives of Internal medicine, 2006; 9: 319-23.

Williams, T.N., B. Wonke, S.M. Donelive: A study of hepatitis B and C prevalence and liver function in multiply transfused thalassemic and their parents, Indian Journal of pediatrics, Vol.29, (Sep1992).

\section{How to cite this article:}

Chandani C. Surani, Ruchi V. Shah and Mala Sinha. 2018. A Study of Prevalence of HepatitisB and Hepatitis-C Infection in Thalassemic Patients in a Tertiary Care Hospital, Jamnagar, Gujarat, India. Int.J.Curr.Microbiol.App.Sci. 7(05): 3142-3146.

doi: https://doi.org/10.20546/ijcmas.2018.705.367 